\title{
Formal-Informal Credit Market Interlinkage and Development Policies: A General Equilibrium Analysis
}

\author{
Rakhi Banerjee1, Ranjanendra Narayan Nag² \\ ${ }^{1}$ Gurudas College, Kolkata, India \\ ${ }^{2}$ St. Xavier's College, Kolkata, India \\ Email: rakhi.banerjee77@gmail.com, rnnag12@gmail.com
}

Received 12 May 2015; accepted 17 August 2015; published 20 August 2015

Copyright (C) 2015 by authors and Scientific Research Publishing Inc.

This work is licensed under the Creative Commons Attribution International License (CC BY).

http://creativecommons.org/licenses/by/4.0/

(c) () Open Access

\begin{abstract}
Globalization has brought about significant changes in the organization of production of emerging market economies. One such change is an emergence of an advanced, export-oriented rural agricultural sector. This advanced sector not only uses land and labor but also uses formal credit for financing its production. This growing importance of formal credit in the agricultural sector motivates us to explore the implications of formal-informal credit market interlinkage using a three sector General Equilibrium trade theoretic structure. In the present paper, we would like to explore the implications of financial deregulation, an increase in amount of formal credit and agricultural trade liberalization. The focus of our examination has been on factor rewards, output composition and national income of a transitional economy. Multiple cross effects, factor intensity ranking and factor specificity are crucial in determining the results.
\end{abstract}

\section{Keywords}

Non-Traded Informal Sector, Modern Agriculture, Formal Credit and Informal Credit

\section{Introduction}

Globalization has brought about significant changes in the organization of production of transitional economies. One such change is the emergence of an advanced agricultural sector. This export oriented agricultural sector of transitional economies not only uses land and labour for production, it also uses formal credit for financing production. Available statistics of transitional economies are suggestive of the formal-informal credit market interlinkage prevalent in the agricultural sector. For example, three major channels for disbursement of formal credit in India are commercial banks, cooperatives and micro-finance institutions (MFI). Casual empiricism suggests 
that in the post globalization era the importance of formal credit has increased substantially in export oriented agricultural sector. The share of formal credit had gone up to over 50\% from the year 1981-1982 [1]. Under the guidance of Reserve Bank of India, public sector banks had prepared Special Agricultural Credit Plans (SACP) in 1994-1995 to increase the flow of formal credit to agricultural sector. With the introduction of SACP, supply of credit to agricultural sector had increased substantially from Rs.8255 crore in 1994-1995 to Rs.122,443 crore in 2006-2007. SACP mechanism had been applicable to private sector banks from the year 2005-2006. Disbursements of formal credit to agriculture by private sector banks under SACP aggregated to Rs.44,093 crore against the target of Rs.40,656 crore in the year 2006-2007 [2]. Notwithstanding, the importance of formal credit in Indian agriculture, the importance of informal credit cannot be overruled. The formal credit delivery to the agriculture sector is still inadequate. Empirical works of Bedback (1986) in Orissa, Sarap [3] in Orissa, highlighted the delay in disbursement of formal credit. The banking system is still hesitant to supply credit to small and marginal farmers. Empirical studies are suggestive of the fact that private money lenders, friends, relatives, commission agents and traders are important agents in the informal credit market (for example, Sarap [3], Das, Senapati, John [2] among others). Gupta and Chaudhuri [1] in their paper develop the idea that farmers have access to both formal and informal credit.

Another development in the post globalization era is the emergence of an informal sector. "Informal sector" covers all small, cottage and family firms [4]. The informal sector is mostly non-traded in nature providing output and services to the formal sector through subcontracting arrangements and also to the general population. Gupta [5], Khan [6]-[7], Grinols [8], Chandra and Khan [9] explored the impact of policy reforms in a situation where informal sector produces non-traded items. Firms in the informal sector can be set up with minimum amounts of capital and without sector specific professional skills. The urban informal sector depends mainly on the unorganized informal credit market for financing its activities (for example, Romatit [10], Sarkar and Ghosh [11], Ghosh [12] among others). There is a voluminous literature on three sector models of transitional economies. The sectors under consideration have mostly been the urban formal sector with an institutionally fixed wage, a rural sector and an urban informal sector (for example, Quibria [13], Grinols [8], Khan [6]-[7], Gupta [5], Chandra, Khan [9] among others).

However, there is hardly any work in the General Equilibrium (GE) frame work which addresses the impact of policy reforms in a set up where formal credit plays an active role in financing the production activities of both urban formal sector and the rural export oriented agricultural sector. To do so is the objective of the paper. Mention may be made in this regarding to the work of Gupta [14] for his contribution to the literature on formal and informal credit market inter-linkage using a GE frame work. However, in Gupta [14] formal capital is used exclusively by the urban sector and not by the rural sector.

The model under consideration is different from other models in its assumption regarding the nature of capital mobility between sectors. There is perfect mobility of informal credit between all the three sectors whereas the formal credit is mobile between urban formal sector and export oriented agricultural sector. Secondly, our paper differs from other papers in its treatment of the relationship between formal credit and informal credit. Gupta and Chaudhuri [1] states formal and informal credit in the agricultural sector can be either complementary or substitutes. In the present paper we treat formal and informal credit as substitutes for one another. Our idea of treating formal and informal credit as substitutes is based on Chaudhuri and Gupta [1], Chaudhuri (2001). According to Chaudhuri and Gupta [1] the market for informal credit comes into existence because the needs of the framers are not satisfied by formal credit since there is a delay in disbursement of formal credit. Chaudhuri (2001) through his model of interaction between two forms of credit markets shows that bank officials often face lending constraints. A situation of inadequate supply of bank credit encourages market of informal credit. The third point of difference of the present from other models is in the treatment of supply of informal credit. Gupta and Chaudhuri [1] highlight that supply of formal credit is exogenously given and the supply is controlled by administrative officials of an economy. According to Gupta and Chaudhuri [1] formal rate of interest is determined administratively. On the other hand, money lenders determine the rate of interest on informal credit. Empirical studies reveal that rates of interest charged by the informal lenders are far higher than the interest rates charged by the formal credit market. The idea of higher rates of return on informal credit have been posited through lenders risk hypothesis ${ }^{1}$ and also the hypothesis presented by Bhadhuri (1977) ${ }^{2}$. The assumption of

\footnotetext{
${ }^{1}$ According to lenders risk hypothesis, a lender faces higher probability of default in the informal credit market and hence the effective rate of interest is lower even though the nominal rate of interest is higher in the informal credit market.

${ }^{2}$ According to Bhadhuri (1977) [15], the lenders hidden objective of acquiring control over the borrowers assets motivates him to charge a higher rate of interest.
} 
higher rate of interest on informal credit has also been established in Gupta and Chaudhuri $[1]^{3}$. Existing theoretical and empirical literature have motivated us to endogenise the supply of informal credit, supply being dependent on the interest rate differential between the formal and informal credit market. The fourth point of departure is in the process of classification of labour force. We assume that skilled labour is not mobile between sectors whereas the unskilled labour force is mobile between informal sector and export oriented agricultural sector. Fifthly, we depart from Gupta [1] by introducing an informal non traded urban sector.

The comparative static exercises performed in this paper are these. In the present paper we would explore the consequences of financial deregulation. Initially the rate of interest on formal credit is far below the market clearing rate of interest due to government regulations. However, with the advent of financial deregulation the prevailing rate of interest would tend to equalize with the market clearing rate of interest. Hence, we posit the issue of financial deregulation in terms of an increase in the rate of interest of formal credit. We would also explore the consequences of an increase in the supply of the formal credit and agricultural trade liberalization. Our prime focus would be to analyze the effect of policy reforms on the output composition, factor rewards and national income of the country. Multiple cross effects, factor intensity ranking and factor specificity are crucial in determining the results. The paper is organized as follows. In Section 2 we set up the basic model. The relevant comparative static exercises are performed in Section 3 of the paper. Section 4 concludes the paper.

\section{The Model}

\subsection{Assumptions and Equations}

We consider a developing economy which is in the process of transition from a controlled regime to a liberalized environment. The economy consists of three sectors. One of the sectors is the import competing urban formal industrial sector, $(\mathrm{X})$. The second sector is the non-traded informal sector producing goods $(\mathrm{Y})$ for the laborers and the third sector is the export oriented modern agricultural sector $(\mathrm{Z})$.

In this model, we introduce the existence of both skilled labour and unskilled labour. The present paper conceptualizes this distinction in terms of the sectors in which they are utilized. To be more specific, the import competing manufacturing sector is produced with the help of skilled labour whereas the informal sector and the export oriented agricultural sector use unskilled labour. The wage of skilled labour and unskilled labour are assumed to be perfectly flexible. Informal sector is utilized in production related activities of all the three sectors. Formal credit is utilized by the urban formal sector and the export oriented agricultural sector. Since, informal credit is perfectly mobile between sectors; we have a common rate of return on informal credit in all the sectors. The institutional rate of return on formal capital is also same in the urban formal sector and the rural sector. We assume that formal credit and informal credit are substitutable in nature. In the present model we have endogenised the supply of informal credit. The supply of informal credit is taken as a function of the relative differential between the interest rates in the informal and formal markets. The supply of formal credit is exogenously given.

The following symbols are used for the formal representation of the model:

$a_{s x}=$ skilled labour coefficient of the manufacturing sector;

$a_{u y}=$ unskilled labour coefficient in informal sector;

$a_{u z}=$ unskilled labour coefficient in modern agriculture;

$a_{k x}=$ formal capital output ratio in the X sector;

$a_{k z}=$ formal capital output ratio in the Z sector;

$a_{k 1 x}=$ informal capital output ratio in the $\mathrm{X}$ sector;

$a_{k 1 z}=$ informal capital output ratio in the $\mathrm{Z}$ sector;

$a_{k 1 y}=$ informal capital output ratio in the Y sector;

$w_{u}=$ wage of unskilled labour;

$w_{s}=$ wage of skilled labour;

$R=$ rate of return on informal credit;

$\bar{r}=$ rate of return on formal credit;

$L_{u}=$ endowment of unskilled labour;

$L_{s}=$ endowment of skilled labour;

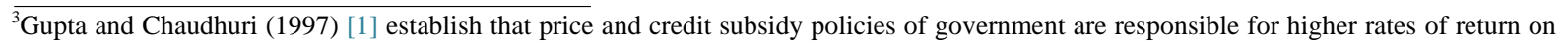
informal credit. The idea holds when formal and informal credit are complementary to each other. 
$K_{f}=$ endowment of formal credit;

$K_{1}=$ endowment of informal credit;

$P_{x}^{*}, P_{z}^{*}=$ international price of commodity $\mathrm{X}$ and $\mathrm{Y}$;

$P_{y}=$ Price of non traded product $\mathrm{Y}$;

$e_{R}=$ change in the endowment of informal credit due to one unit change in rate of return on informal credit;

$e_{r}=$ change in the endowment of informal credit due to one unit change in rate of return on formal credit;

$\theta_{s x}=$ distribution share of skilled labour in production of $\mathrm{X}$;

$\theta_{u y}=$ distribution share of unskilled labour in production of $\mathrm{Y}$;

$\theta_{u z}=$ distribution share of unskilled labour in production of Z;

$\theta_{k x}=$ distribution share of formal credit in production of X;

$\theta_{k z}=$ distribution share of formal credit in production of $\mathrm{Z}$;

$\theta_{k i y}=$ distribution share of informal credit in production of $\mathrm{Y}$;

$\theta_{k 1 z}=$ distribution share of informal credit in production of Z;

$\theta_{k 1 x}=$ distribution share of informal credit in production of $\mathrm{X}$;

$\lambda_{s x}=$ proportion of skilled labour employed in $\mathrm{X}$;

$\lambda_{u y}=$ proportion of unskilled labour employed in $\mathrm{Y}$;

$\lambda_{u z}=$ proportion of unskilled labour employed in $\mathrm{X}$;

$\lambda_{k x}=$ proportion of formal capital employed in $\mathrm{X}$;

$\lambda_{k z}=$ proportion of formal capital employed in $\mathrm{Z}$;

$\lambda_{k 1 y}=$ proportion of informal capital employed in $\mathrm{Y}$;

$\lambda_{k 1 z}=$ proportion of informal capital employed in Z;

$\lambda_{k 1 x}=$ proportion of informal capital employed in $\mathrm{X}$;

$T=$ income of the economy.

The general equilibrium structure of the model is as follows.

Given the assumption of perfectly competitive markets, the usual price unit cost equality conditions relating to the three sectors of the economy are given by the following three equations, respectively:

$$
\begin{gathered}
a_{s x} \cdot w_{s}+a_{k 1 x} R=P_{x}^{*} \\
a_{u y} \cdot w_{u}+a_{k 1 y} \cdot R=P_{y} \\
a_{u z} \cdot w_{u}+a_{k 1 z} \cdot R=P_{z}^{*}
\end{gathered}
$$

Since, interest rate in formal credit market is administered, additional demand for credit is met by informal credit at market clearing interest rate. Hence, interest rate on informal credit figures in the cost of production.

Given the full employment condition, the endowment equations are given as follows:

$$
\begin{gathered}
a_{s x} X=L_{s} \\
a_{u y} \cdot Y+a_{u z} \cdot Z=L_{u} \\
\left(a_{k x}+a_{k 1 x}\right) X+a_{k 1 y} Y+\left(a_{k z}+a_{k i z}\right) Z=K_{f}+K_{1}(R-\bar{r})
\end{gathered}
$$

It is assumed that a fraction of the total wage income is spent on the produce of the informal sector. Thus, we have:

$$
\alpha\left(w_{u} L_{u}+w_{s} L_{s}\right)=P_{y} Y, \quad 0<\alpha<1
$$

The total factor income of the economy is given by the following equation

$$
T=w_{s} L_{s}+w_{u} L_{u}+R K_{1}(R-\bar{r})+\bar{r} K_{f}
$$

The sufficient condition for stability in this model is as follows:

$$
-\frac{\lambda_{u y}}{\lambda_{u z}}\left(\lambda_{k z} K_{f}+\lambda_{k 1 z} K_{1}\right)+\lambda_{k 1 y} K_{1}^{4}
$$

${ }^{4}$ See mathematical appendix for detailed derivation of stability condition. 


\subsection{Working of the Model}

The working of the model is as follows. The endogenous variables of the model are price of traditional agricultural product, wage of skilled labour, wage of unskilled labour, rate of return on informal capital, amount of manufacturing good produced, amount of modern agricultural product produced, amount of non traded informal sector good produced, supply of informal capital and total factor income of the country. The endogenous variables are determined simultaneously from Equations (1) to (8). Given supply of skilled labour, amount of formal sector produce (X) is determined from Equation (4). From Equations (2) and (3), we determine wage of unskilled labour $\left(w_{u}\right)$ and return on informal capital $(R)$. From Equation (1) we determine wage of skilled labour $\left(w_{s}\right)$. From Equations (5) and (6) we determine amount of non traded informal sector produce (Y), amount of agricultural produce $(\mathrm{Z})$ and amount of informal sector credit $\left(K_{1}\right)$. From Equation $(7)$ we determine price of informal sector product $\left(P_{y}\right)$. From Equation (8) we determine the total factor rewards of the economy $(T)$.

\section{Comparative Static Analysis}

In this section we carry out some comparative static exercises to analyze the impact of an increase in the rate of interest of formal credit, an increase in the endowment of formal credit and agricultural trade liberalization.

First, we would concentrate on the effect of financial deregulation.

Proposition 1: If non-traded informal sector uses informal credit more intensively compared to the agricultural sector, rate of return on informal credit rises whereas wage of both skilled and unskilled labour falls with an increase in the rate of return of formal credit provided:

$$
K_{1} e_{r}-\frac{1}{\theta_{k x}+\theta_{k 1 x}} \sigma_{k, k 1}^{x}\left[\lambda_{k x} \theta_{k 1 x}-\lambda_{k 1 x} \theta_{k x}\right]+\frac{\sigma_{k, k 1}^{2}}{\theta_{k z}+\theta_{k 1 z}}\left[\lambda_{k 1 z} \theta_{k z}-\lambda_{k z} \theta_{k 1 z}\right]<0 .
$$

The skill intensive sector remains unchanged. However, the non traded informal sector expands in size whereas the traded agricultural sector contracts if:

$$
K_{1} e_{R}-\frac{1}{\theta_{k x}+\theta_{k 1 x}} \sigma_{k, k 1}^{x}\left[\lambda_{k x} \theta_{k 1 x}-\lambda_{k 1 x} \theta_{k x}\right]+\frac{\sigma_{k, k 1}^{z}}{\theta_{k z}+\theta_{k 1 z}}\left[\lambda_{k 1 z} \theta_{k z}-\lambda_{k z} \theta_{k 1 z}\right]>0
$$

Comment: Differentiating Equations (1)-(7) we find ${ }^{5}$ :

$$
\begin{gathered}
\hat{P}_{y}=-\frac{1}{M_{3} M_{1}} L_{2} P_{y} Y \hat{\bar{r}} \\
\hat{R}=-\frac{1}{M_{3} M_{1}} L_{2} P_{y} Y \hat{\bar{r}} \frac{1}{D} \frac{\theta_{u z}}{\theta_{k 1 z}} \\
\hat{w}_{s}=\frac{1}{M_{3} M_{1}} L_{2} P_{y} Y \hat{\bar{r}} \frac{1}{D} \frac{\theta_{u z} \theta_{k i x}}{\theta_{k 1 z} \theta_{s x}} \\
\hat{w}_{u}=\frac{1}{M_{3} M_{1}} L_{2} P_{y} Y \hat{\bar{r}} \frac{1}{D} \\
\hat{Y}=\frac{1}{M_{1}}\left[-\frac{1}{M_{3} M_{1}} L_{2} P_{y} Y \hat{\bar{r}} \frac{1}{D} \frac{\theta_{u z}}{\theta_{k 1 z}} L_{1}-\hat{\bar{r}} L_{2}\right] \\
\hat{Z}=-\frac{\lambda_{u y}}{\lambda_{u z}} \frac{1}{M_{1}}\left[-\frac{1}{M_{3} M_{1}} L_{2} P_{y} Y \hat{\bar{r}} \frac{1}{D} \frac{\theta_{u z}}{\theta_{k 1 z}} L_{1}-\hat{\bar{r}} L_{2}\right]
\end{gathered}
$$

where,

${ }^{5}$ See mathematical appendix for detailed derivation. 


$$
\begin{gathered}
M_{1}=-\frac{\lambda_{u y}}{\lambda_{u z}}\left(\lambda_{k z}+\lambda_{k 1 z}\right)+\lambda_{k 1 y}>0^{6} \\
M_{3}=\frac{\alpha}{D}\left(w_{u} L_{u}+\frac{w_{s} L_{s} \theta_{k 1 x} \theta_{u z}}{\theta_{k 1 z} \theta_{s x}}\right)+P_{y} Y\left(\frac{L_{1}}{D M_{1}} \frac{\theta_{u z}}{\theta_{k 1 z}}-1\right)<0 \\
L_{1}=K_{1} e_{R}-\frac{1}{\theta_{k x}+\theta_{k 1 x}} \sigma_{k, k 1}^{x}\left[\lambda_{k x} \theta_{k 1 x}-\lambda_{k 1 x} \theta_{k x}\right]+\frac{\sigma_{k, k 1}^{z}}{\theta_{k z}+\theta_{k 1 z}}\left[\lambda_{k 1 z} \theta_{k z}-\lambda_{k z} \theta_{k 1 z}\right] \\
L_{2}=K_{1} e_{r}-\frac{1}{\theta_{k x}+\theta_{k 1 x}} \sigma_{k, k 1}^{x}\left[\lambda_{k x} \theta_{k 1 x}-\lambda_{k 1 x} \theta_{k x}\right]+\frac{\sigma_{k, k 1}^{z}}{\theta_{k z}+\theta_{k 1 z}}\left[\lambda_{k 1 z} \theta_{k z}-\lambda_{k z} \theta_{k 1 z}\right] \\
D=\theta_{u y}-\frac{\theta_{u z} \theta_{k 1 y}}{\theta_{k 1 z}}<0^{7}
\end{gathered}
$$

On the assumption that the urban informal sector uses informal credit more intensively compared to the rural agricultural sector, financial deregulation may increase the rate of return on informal credit if:

$$
e_{r} K_{1}-\frac{1}{\theta_{k x}+\theta_{k 1 x}} \sigma_{k, k 1}^{x}\left[\lambda_{k x} \theta_{k 1 x}-\lambda_{k 1 x} \theta_{k x}\right]+\frac{\sigma_{k, k 1}^{2}}{\theta_{k z}+\theta_{k 1 z}}\left[\lambda_{k 1 z} \theta_{k z}-\lambda_{k z} \theta_{k 1 z}\right]<0
$$

Following Stolper Samuelson theorem, wage of both skilled and unskilled laborer would decline. Hence, in terms of income distribution, both skilled and unskilled laborers are adversely affected. On the other hand, credit suppliers of the economy benefit from financial deregulation.

Change in rate of interest does not affect the production level of the formal sector. This is because of the fact that there is no change in the endowment level of specific factor (skilled labour) used in the urban formal sector. However, financial deregulation increases the rate of return on both types of capital. Since, supply of informal credit has been taken to be a function of the relative differential between the interest rates in the informal and formal market, the change in interest rates of both formal and informal credit affects the endowment level of informal credit. If the condition stated in Equation (16) is satisfied, then the informal sector would expand provided:

$$
-\frac{1}{\theta_{k x}+\theta_{k 1 x}} \sigma_{k, k 1}^{x}\left[\lambda_{k x} \theta_{k 1 x}-\lambda_{k 1 x} \theta_{k x}\right]+\frac{\sigma_{k, k 1}^{z}}{\theta_{k z}+\theta_{k 1 z}}\left[\lambda_{k 1 z} \theta_{k z}-\lambda_{k z} \theta_{k 1 z}\right]>0
$$

Following Rybzynscki argument, the export oriented agricultural sector would contract in size.

We also find that the price of the non traded sector falls. The explanation is this. We know from Equation (7) that: $\alpha\left(w_{u} L_{u}+w_{s} L_{s}\right)=P_{y} Y, 0<\alpha<1$ (7). Following financial deregulation, wage of skilled labour as well as unskilled labour falls. On the other hand, the production of non traded informal sector rises. Hence, to maintain equilibrium in the non traded sector, price of the non traded item falls.

Proposition 2: Following financial deregulation, the total factor income of the economy may increase if:

$$
w_{s} L_{s}\left(\frac{\theta_{k 1 x} \theta_{u z}}{\theta_{k 1 z} \theta_{s x}}\right)+w_{u} L_{u}-R K_{1}\left(1+e_{R}\right) \frac{\theta_{u z}}{\theta_{k 1 z}}<0
$$

Comment: The total factor income of the economy is given by the following equation

$$
T=w_{s} L_{s}+w_{u} L_{u}+R K_{1}(R-\bar{r})+\bar{r} K_{f}
$$

An increase in interest rate of formal credit affects the total factor income of the economy by altering factor rewards and also endowment level of informal credit. Differentiating the above equation we find that:

$$
\mathrm{d} T=w_{s} \hat{w}_{s} L_{s}+w_{u} \hat{w}_{u} L_{u}+R K_{1} \hat{R}\left[1+e_{R}\right]+\hat{\bar{r}}\left[K_{f} \bar{r}-R K_{1} e_{r}\right]
$$

Substituting the values of the endogenous variables, the above equation can be rewritten as:

${ }^{6}$ Follows from stability condition.

${ }^{7} \mathrm{D}<0$ if non traded informal sector uses informal credit more intensively compared to the agricultural sector. 


$$
\hat{\bar{r}}\left[\frac{L_{2} P_{y} Y}{M_{3} M_{1} D}\left\{w_{s} L_{s}\left(\frac{\theta_{k 1 x} \theta_{u z}}{\theta_{k 1 z} \theta_{s x}}\right)+w_{u} L_{u}-R K_{1}\left(1+e_{R}\right) \frac{\theta_{u z}}{\theta_{k 1 z}}\right\}-\left\{K_{f} \bar{r}-R K_{1} e_{r}\right\}\right]
$$

From the proceeding analysis we find that decline in the wage of skilled and unskilled labour would suppress total factor income of the economy. On the other hand, the rise in interest rates of both types of credit would help in increasing the total factor income of the economy. Sufficient condition for income to increase is:

$$
\frac{L_{2} P_{y} Y}{M_{3} M_{1} D}\left\{w_{s} L_{s}\left(\frac{\theta_{k 1 x} \theta_{u z}}{\theta_{k 1 z} \theta_{s x}}\right)+w_{u} L_{u}-R K_{1}\left(1+e_{R}\right) \frac{\theta_{u z}}{\theta_{k 1 z}}\right\}-\left\{K_{f} \bar{r}-R K_{1} e_{r}\right\}>0
$$

We would now examine the effect of an increase the endowment level of formal credit.

Proposition 3: If the informal sector uses informal type of credit more intensively than the agricultural sector and

$$
K_{1} e_{R}-\frac{1}{\theta_{k x}+\theta_{k 1 x}} \sigma_{k, k 1}^{x}\left[\lambda_{k x} \theta_{k 1 x}-\lambda_{k 1 x} \theta_{k x}\right]+\frac{\sigma_{k, k 1}^{z}}{\theta_{k z}+\theta_{k 1 z}}\left[\lambda_{k 1 z} \theta_{k z}-\lambda_{k z} \theta_{k 1 z}\right]>0,
$$

an increase in the endowment of formal credit would increase the wage of both skilled and unskilled labour. On the other hand, increase in the level of formal credit would depress the rate of return of informal credit. Following increase in supply of formal credit, the non traded informal sector expands in size and the traded agricultural sector to contracts.

Comment: Differentiating Equations (1) to (7) we have ${ }^{8}$ :

$$
\begin{gathered}
\hat{P}_{y}=\frac{1}{M_{3}} P_{y} Y \frac{1}{M_{1}} K_{f} \hat{K}_{f} \\
\hat{w}_{u}=\frac{1}{M_{3}} \frac{1}{D} P_{y} Y \frac{1}{M_{1}} K_{f} \hat{K}_{f} \\
\hat{R}=-\frac{\theta_{u z}}{\theta_{k 1 z}} \frac{1}{M_{3}} \frac{1}{D} P_{y} Y \frac{1}{M_{1}} K_{f} \hat{K}_{f} \\
\hat{w}_{s}=\frac{\theta_{k 1 x}}{\theta_{k 1 z}} \frac{\theta_{u z}}{\theta_{s x}} \frac{1}{M_{3}} \frac{1}{D} P_{y} Y \frac{1}{M_{1}} K_{f} \hat{K}_{f} \\
\hat{Y}=\frac{L_{1}}{M_{1}}\left[-\frac{\theta_{u z}}{\theta_{k 1 z}} \frac{1}{M_{3}} \frac{1}{D} P_{y} Y \frac{1}{M_{1}} K_{f}\right] \hat{K}_{f}+\frac{1}{M_{1}} K_{f} \hat{K}_{f} \\
\hat{Z}=-\frac{\lambda_{u y}}{\lambda_{u z}}\left\{\frac{L_{1}}{M_{1}}\left[-\frac{\theta_{u z}}{\theta_{k 1 z}} \frac{1}{M_{3}} \frac{1}{D} P_{y} Y \frac{1}{M_{1}} K_{f}\right] \hat{K}_{f}+\frac{1}{M_{1}} K_{f} \hat{K}_{f}\right\}
\end{gathered}
$$

where,

$$
\begin{gathered}
M_{1}=-\frac{\lambda_{u y}}{\lambda_{u z}}\left(\lambda_{k z}+\lambda_{k 1 z}\right)+\lambda_{k 1 y} \\
M_{3}=\frac{\alpha}{D}\left(w_{u} L_{u}+\frac{w_{s} L_{s} \theta_{k 1 x} \theta_{u z}}{\theta_{k 1 z} \theta_{s x}}\right)+P_{y} Y\left(\frac{L_{1}}{D M_{1}} \frac{\theta_{u z}}{\theta_{k 1 z}}-1\right) \\
L_{1}=K_{1} e_{R}-\frac{1}{\theta_{k x}+\theta_{k 1 x}} \sigma_{k, k 1}^{x}\left[\lambda_{k x} \theta_{k 1 x}-\lambda_{k 1 x} \theta_{k x}\right]+\frac{\sigma_{k, k 1}^{z}}{\theta_{k z}+\theta_{k 1 z}}\left[\lambda_{k 1 z} \theta_{k z}-\lambda_{k z} \theta_{k 1 z}\right]
\end{gathered}
$$

${ }^{8}$ See Mathematical appendix for detailed derivation. 


$$
D=\theta_{u y}-\frac{\theta_{u z} \theta_{k 1 y}}{\theta_{k 1 z}}
$$

Given the fact that informal sector uses informal credit more intensively compared to the agricultural sector, an increase in the supply of formal credit would decrease the price of non traded item in the market. As the price of the non-traded item increases, from the Stolper Samuelson theorem we find rate of return on informal credit decreases. From Equations (1) and (3) we can conclude that wage of skilled laborers and unskilled laborers increase.

The effect on output composition requires a careful analysis. Since, the specific factor endowment remain unchanged, there is no change in the production level of the urban formal sector. Along with the change in the endowment of formal credit, the supply of informal credit also decreases. This is because of the fact that the interest rate differential between informal credit and formal credit decreases. A decrease in $\left(\frac{R}{r}\right)$ changes factor coefficients leading to a further decline in the endowment of informal credit. Inspite of a decrease in the availability of informal credit, the informal sector expands in size. The explanation is this. However, since a fraction of wage earners income is spent on non traded items, an increase in the wage levels increase the demand for non-traded items. It should also be noted that the change in the endowment level of formal capital depresses the price of the informal sector produce. Hence, the left hand side of Equation (7) exceeds the right hand side. To restore equilibrium in the non traded product market, the non-traded sector expands in size. Following Rybzynscki argument there would be a decline in the production of the agricultural sector.

Proposition 4: If the endowment level of formal credit increases, the total factor income of the economy may increase if:

$$
w_{u} L_{u}-w_{s} L_{s} \frac{\theta_{u z} \theta_{k 1 x}}{\theta_{k 1 z} \theta_{s x}}-R K_{1} \frac{\theta_{u z}}{\theta_{k 1 z}}>0
$$

Comment: The total factor income of the economy is given by the following equation:

$$
T=w_{s} L_{s}+w_{u} L_{u}+R K_{1}(R-\bar{r})+\bar{r} K_{f}
$$

An increase in supply formal credit affects the total factor income of the economy by affecting both factor rewards and endowment level of informal credit. Differentiating the above equation we find that:

$$
\mathrm{d} T=w_{s} \hat{w}_{s} L_{s}+w_{u} \hat{w}_{u} L_{u}+R K_{1} \hat{R}\left[1+e_{R}\right]+\bar{r} K_{f} \hat{K}_{f}
$$

Substituting the values of the endogenous variables in the above equation we find:

$$
\left[\left\{w_{u} L_{u}+w_{s} L_{s} \frac{\theta_{u z} \theta_{k 1 x}}{\theta_{k 1 z} \theta_{s x}}-R K_{1} \frac{\theta_{u z}}{\theta_{k 1 z}}\left(1+e_{R}\right)+\bar{r} K_{f}\right\} \frac{P_{y} Y}{M_{3} M_{1} D}\right] K_{f} \hat{K}_{f}
$$

From the preceeding analysis we find that increase in the wage of skilled and unskilled labour would increase total factor income of the economy. Even though the institutionally given formal interest rate remains unaffected, the increase in the endowment level of formal credit acts as a facilitator in improving the total factor income of the economy. On the other hand, a fall in interest rate of informal credit would suppress the total factor income of the economy. The fall in the level of informal credit leads to a further decline in the total factor income of the economy. Sufficient condition for income to increase is:

$$
w_{u} L_{u}+w_{s} L_{s} \frac{\theta_{u z} \theta_{k 1 x}}{\theta_{k 1 z} \theta_{s x}}-R K_{1} \frac{\theta_{u z}}{\theta_{k 1 z}}\left(1+e_{R}\right)+\bar{r} K_{f}>0
$$

We would mow concentrate on the effect of agricultural trade liberalization.

Proposition 5: If the informal sector uses informal credit more intensively compared to the agricultural sector and

$$
K_{1} e_{R}-\frac{1}{\theta_{k x}+\theta_{k 1 x}} \sigma_{k, k 1}^{x}\left[\lambda_{k x} \theta_{k 1 x}-\lambda_{k 1 x} \theta_{k x}\right]+\frac{\sigma_{k, k 1}^{z}}{\theta_{k z}+\theta_{k 1 z}}\left[\lambda_{k 1 z} \theta_{k z}-\lambda_{k z} \theta_{k 1 z}\right]>0,
$$


rate of return on informal credit and wage of unskilled laborers increase whereas wage of skilled laborers decrease if: $\left[\frac{\theta_{u y}}{\theta_{u z}}-\frac{1}{N_{1}}\right]<0$. The production level of the skill intensive sector remains unchanged. However, the production level of informal sector increases and the production level of agricultural sector decreases.

Comment: Differentiating Equations (1) to (7) we have':

$$
\begin{gathered}
\hat{P}_{y}=\frac{1}{N_{1}} \hat{P}_{z}^{*} \\
\hat{R}=\frac{1}{D}\left[\frac{\theta_{u y}}{\theta_{u z}}-\frac{1}{N_{1}}\right] \hat{P}_{z}^{*} \\
\hat{w}_{u}=\frac{\theta_{k 1 z}}{\theta_{u z}} \hat{P}_{z}^{*} \frac{1}{N_{1}}+\left[1-\frac{\theta_{k 1 z} \theta_{u y}}{D \theta_{u z}}\right] \frac{\hat{P}_{z}^{*}}{\theta_{u z}} \\
\hat{w}_{s}=\frac{1}{D} \frac{\theta_{k 1 x}}{\theta_{s x}} \hat{P}_{z}^{*}\left[\frac{1}{N_{1}}-\frac{\theta_{u y}}{\theta_{u z}}\right] \\
\hat{Y}=\frac{L_{1}}{M_{1}} \frac{1}{D}\left[\frac{\theta_{u y}}{\theta_{u z}}-\frac{1}{N_{1}}\right] \hat{P}_{z}^{*} \\
\hat{Z}=-\frac{\lambda_{u y}}{\lambda_{u z}} \frac{L_{1}}{M_{1}} \frac{1}{D}\left[\frac{\theta_{u y}}{\theta_{u z}}-\frac{1}{N_{1}}\right] \hat{P}_{z}^{*}
\end{gathered}
$$

where,

$$
\begin{gathered}
M_{1}=-\frac{\lambda_{u y}}{\lambda_{u z}}\left(\lambda_{k z}+\lambda_{k 1 z}\right)+\lambda_{k 1 y} \\
M_{3}=\frac{\alpha}{D}\left(w_{u} L_{u}+\frac{w_{s} L_{s} \theta_{k 1 x} \theta_{u z}}{\theta_{k 1 z} \theta_{s x}}\right)+P_{y} Y\left(\frac{L_{1}}{D M_{1}} \frac{\theta_{u z}}{\theta_{k 1 z}}-1\right) \\
L_{1}=K_{1} e_{R}-\frac{1}{\theta_{k x}+\theta_{k 1 x}} \sigma_{k, k 1}^{x}\left[\lambda_{k x} \theta_{k 1 x}-\lambda_{k 1 x} \theta_{k x}\right]+\frac{\sigma_{k, k 1}^{z}}{\theta_{k z}+\theta_{k 1 z}}\left[\lambda_{k 1 z} \theta_{k z}-\lambda_{k z} \theta_{k 1 z}\right] \\
L_{2}=e_{r}-\frac{1}{\theta_{k x}+\theta_{k 1 x}} \sigma_{k, k 1}^{x}\left[\lambda_{k x} \theta_{k 1 x}-\lambda_{k 1 x} \theta_{k x}\right]+\frac{\sigma_{k, k 1}^{z}}{\theta_{k z}+\theta_{k 1 z}}\left[\lambda_{k 1 z} \theta_{k z}-\lambda_{k z} \theta_{k 1 z}\right] \\
D=\theta_{u y}-\frac{\theta_{u z} \theta_{k 1 y}}{\theta_{k 1 z}}<0 \\
N_{1}=\frac{P_{y} Y L_{1} \theta_{u y}}{M_{3} D M_{1} \theta_{u z}} \frac{1}{1+\frac{P_{y} Y L_{1}}{M_{3} M_{1} D}}>0
\end{gathered}
$$

From Stolper Samuelson theorem we find that as price of agricultural product increases, wage of unskilled laborers increases unambiguously. An increase in the price of agricultural product raises the price of non traded item also. The right hand side of Equation (2) rises. From Equation (2) we conclude that rate of return on infor- 
mal credit would also increase if:

$$
\left[\frac{\theta_{u y}}{\theta_{u z}}-\frac{1}{N_{1}}\right]<0
$$

If rate of return on informal credit increases, from Equation (1) we can state that wage of skilled workers would decrease to maintain unit cost price equality.

We now analyze the effect on output composition. Since, the specific factor endowment, skilled labour remains unchanged there is no change in the production level of the urban formal sector. An increase in rate of interest of informal credit increases the supply of informal credit. This increase in supply of informal credit increases the production of non traded informal sector produce ${ }^{10}$. Since, agricultural sector also uses informal credit for production, following Rybzynscki argument there would be a decrease in the production of the agricultural sector.

Proposition 6: If the endowment level of skilled laborers increases, the total factor income of the economy may increase if:

$$
R K_{1}\left(1+e_{R}\right) \frac{1}{D}\left[\frac{\theta_{u y}}{\theta_{u z}}-\frac{1}{N_{1}}\right]+w_{u} L_{u}\left\{\frac{\theta_{k 1 z}}{\theta_{u z}} \frac{1}{N_{1}}+\left[1-\frac{\theta_{k 1 z} \theta_{u y}}{D \theta_{u z}}\right] \frac{1}{\theta_{u z}}\right\}+w_{s} L_{s} \frac{1}{D} \frac{\theta_{k 1 x}}{\theta_{s x}}\left[\frac{1}{N_{1}}-\frac{\theta_{u y}}{\theta_{u z}}\right]>0
$$

Comment: The total factor income of the economy is given by the following equation

$$
T=w_{s} L_{s}+w_{u} L_{u}+R K_{1}(R-\bar{r})+\bar{r} K_{f}
$$

Agricultural trade liberalization affects the total factor income of the economy by affecting both factor rewards and endowment level of informal credit. Differentiating the above equation we find that:

$$
\mathrm{d} T=w_{s} \hat{w}_{s} L_{s}+w_{u} \hat{w}_{u} L_{u}+R K_{1} \hat{R}\left[1+e_{R}\right]
$$

Substituting the endogenous variables in the above equation the above equation can be rewritten as:

$$
P_{z}^{*} \hat{P}_{z}^{*}\left[R K_{1}\left(1+e_{R}\right) \frac{1}{D}\left[\frac{\theta_{u y}}{\theta_{u z}}-\frac{1}{N_{1}}\right]+w_{s} L_{s} \frac{1}{D} \frac{\theta_{k 1 x}}{\theta_{s x}}\left[\frac{1}{N_{1}}-\frac{\theta_{u y}}{\theta_{u z}}\right] w_{u} L_{u}\left\{\frac{\theta_{k 1 z}}{\theta_{u z}} \frac{1}{N_{1}}+\left[1-\frac{\theta_{k 1 z} \theta_{u y}}{D \theta_{u z}}\right] \frac{1}{\theta_{u z}}\right\}\right]
$$

From the preceding analysis we find that decrease in the wage of skilled would suppress total factor income of the economy. On the other hand, an increase in interest rate of informal credit and wage of unskilled laborers increase total factor income of the economy. The increase in the level of informal credit leads to a further increase in the total factor income of the economy. Hence, sufficient condition for income to increase is:

$$
R K_{1}\left(1+e_{R}\right) \frac{1}{D}\left[\frac{\theta_{u y}}{\theta_{u z}}-\frac{1}{N_{1}}\right]+w_{u} L_{u}\left\{\frac{\theta_{k 1 z}}{\theta_{u z}} \frac{1}{N_{1}}+\left[1-\frac{\theta_{k 1 z} \theta_{u y}}{D \theta_{u z}}\right] \frac{1}{\theta_{u z}}\right\}+w_{s} L_{s} \frac{1}{D} \frac{\theta_{k 1 x}}{\theta_{\text {sx }}}\left[\frac{1}{N_{1}}-\frac{\theta_{u y}}{\theta_{u z}}\right]>0
$$

\section{Conclusion}

The present paper constructs a general equilibrium model to examine implications of financial deregulation, an increase in supply of formal credit and agricultural trade liberalisation. The focus of the analysis has been explored the effect on output composition, factor rewards, income distribution and total factor income of the economy. In the present paper we have assumed that the rate of interest on formal credit is institutionally given and is lower than the market clearing rate of interest. A parametric rise in formal credit interest rate adversely affects wage earners and is beneficial for credit providers in terms of factor rewards. The informal sector expands in size whereas the agricultural sector contracts. On the other hand, if the formal credit base of the economy is augmented, factor rewards of the laborers increase whereas the factor reward of informal credit decreases.

${ }^{10}$ Agricultural trade liberalization augments price of non traded item. The production level of the non traded item also increases. Hence, right hand side of Equation (7) goes up. We note that wage of unskilled laborers go up which implies that demand for non traded item has gone up. However, since the wage of skilled workers fall, there is a decrease in the demand for the product. However, since non traded market equilibrium has to be maintained it implies that the total level of demand has gone up. 
Even though the level of formal credit increases, the agricultural sector which uses formal credit contracts in size whereas the informal sector expands in size. The output level of the formal sector remains unaffected in the two situations under consideration. In both the policy reform measures there is a possibility that total factor income of the economy will increase. Agricultural trade liberalization leads to an expansion in the production level of the informal sector. The agricultural sector is adversely affected in terms of production. This policy reform measure also leads to the worsening of income distribution between skilled laborers and credit providers. There is also a worsening of income distribution between two types of labour. However, the total factor income of the economy may increase. In times of globalization, worsening income distribution and a fall in total factor rewards of the economy are disturbing global phenomena. Hence, the sequence, speed and modalities of globalization need to be judiciously worked out.

\section{Acknowledgements}

We are grateful to Prof. M.R. Gupta and Prof. S. Chaudhuri for comments and encouragements. However, the usual disclaimer is applied.

\section{References}

[1] Gupta, M.R. and Chaudhuri, S. (1997) Formal Credit, Corruption and the Informal Credit Market in Agriculture: A Theoratical Analysis. Economica, 64, 331-343. http://dx.doi.org/10.1111/1468-0335.00081

[2] Das, A., Senapati, M. and John. J. (2009) Impact of Agricultural Credit on Agriculture Production: An Empirical Analysis in India. International Journal of Advanced Research in Management and Social Sciences, 3, 75-107.

[3] Sarap, K. (1990) Factors Affecting Small Farmers’ Access to Institutional Credit in Rural Orissa. Development and Change, 21, 281-307. http://dx.doi.org/10.1111/j.1467-7660.1990.tb00378.x

[4] Fukuchi, T. (1998) A Simulation Analysis of the Urban Informal Sector. The Developing Economies, XXXV1-3, 225256.

[5] Gupta, M.R. (1993) Rural-Urban Migration, Informal Sector and Development Policies: A Theoretical Analysis. Journal of Development Economics, 41, 137-151. http://dx.doi.org/10.1016/0304-3878(93)90040-T

[6] Khan, M.A. (1992) On Measuring the Social Opportunity Cost of Labour in the Presence of a Tariff and an Informal Sector. Pakistan Development Review, 31, 535-562.

[7] Khan, M.A. (1992) Trade and Development in the Presence of an Informal Sector: A Four-Sector Model. In: Basu, K., et al., Eds., Capital, Investment and Development, Basil Blackwell, Oxford.

[8] Grinols, E. (1991) Unemployment and Foreign Capital: The Relative Opportunity Costs of Domestic Labour and Welfare. Economica, 58, 107-121. http://dx.doi.org/10.2307/2554978

[9] Chandra, V. and Khan, M.A. (1993) Foreign Investment in the Presence of an Informal Sector. Economica, 60, 79-103. http://dx.doi.org/10.2307/2554732

[10] Romatet, E. (1983) Calcutta’s Informal Sector: Theory and Reality. Economic and Political Weekly, 18, $2115-2128$.

[11] Sarkar, A. and Ghosh, M. (1989) A Model of the Informal Sector. Indian Statistical Institute Working Paper.

[12] Ghosh, M. (1991) Subcontracting, Subsidized Credit and the Informal Sector. Indian Statistical Institute Working Paper.

[13] Quibria, M.G. (1988) Migration, Trade Unions, and the Informal Sector: A Note on Calvo. International Economic Review, 29, 557-563.

[14] Gupta, M.R. (1995) Informal Sector and Informal Capital Market in a Small Open Less-Developed Economy. Journal of Development Economics, 52, 409-428. http://dx.doi.org/10.1016/S0304-3878(96)00445-2

[15] Bhaduri, A. (1977) On the Formation of Usurious Interest Rates in Backward agriculture. Cambridge Journal of Economics, 1, 341-352. 


\section{Mathematical Appendix}

Given the assumption of perfectly competitive markets, the usual price unit cost equality conditions relating to the three sectors of the economy are given by the following three equations, respectively:

$$
\begin{gathered}
a_{s x} \cdot w_{s}+a_{k 1 x} R=P_{x}^{*} \\
a_{u y} \cdot w_{u}+a_{k 1 y} \cdot R=P_{y} \\
a_{u z} \cdot w_{u}+a_{k 1 z} \cdot R=P_{z}^{*}
\end{gathered}
$$

Given the full employment condition, the endowment equations are given as follows:

$$
\begin{gathered}
a_{s x} X=L_{s} \\
a_{u y} \cdot Y+a_{u z} \cdot Z=L_{u} \\
\left(a_{k x}+a_{k 1 x}\right) X+a_{k 1 y} Y+\left(a_{k z}+a_{k i z}\right) Z=K_{f}+K_{1}(R-\bar{r})
\end{gathered}
$$

It is assumed that a fraction of the total wage income is spent on the produce of the informal sector. Thus, we have:

$$
\alpha\left(w_{u} L_{u}+w_{s} L_{s}\right)=P_{y} Y, \quad 0<\alpha<1
$$

The total factor income of the economy is given by the following equation

$$
T=w_{s} L_{s}+w_{u} L_{u}+R K_{1}(R-\bar{r})+\bar{r} K_{f}
$$

\section{Effect of financial deregulation}

Differentiating Equations (1)-(3) we find:

$$
\begin{gathered}
\hat{R}=-\frac{\theta_{u z}}{\theta_{k 1 z}} \hat{w}_{u} \\
\hat{w}_{u}=\frac{1}{D} \hat{P}_{y} \\
\hat{w}_{s}=\frac{1}{\theta_{s x} \theta_{k 1 z}} \frac{\theta_{k 1 x} \theta_{u z}}{D} \hat{P}_{y}
\end{gathered}
$$

Differentiating Equation (5) we have:

$$
\lambda_{u y} \hat{Y}+\lambda_{u z} \hat{Z}=0
$$

Differentiating Equation (6) we have:

$$
\lambda_{k 1 y} \hat{Y}+\hat{Z}\left\{\lambda_{k z}+\lambda_{k 1 z}\right\}=-\lambda_{k 1 z} \hat{a}_{k 1 z}-\lambda_{k z} \hat{a}_{k z}-\lambda_{k x} \hat{a}_{k x}-\lambda_{k 1 x} \hat{a}_{k 1 x}+K_{1} e_{R} \hat{R}-K_{1} e_{r} \hat{\bar{r}}
$$

Using Equations (d), (e) and the fact that:

$$
\begin{gathered}
\frac{\hat{a}_{k z}-\hat{a}_{k 1 z}}{\hat{R}-\hat{\bar{r}}}=\sigma_{k, k 1}^{z} \\
\frac{\hat{a}_{k x}-\hat{a}_{k 1 x}}{\hat{R}-\hat{\bar{r}}}=\sigma_{k, k 1}^{x} \\
\lambda_{k 1 y} \hat{Y}+\hat{Z}\left\{\lambda_{k z}+\lambda_{k 1 z}\right\}=\hat{R} L_{1}-\hat{r} L_{2} \\
\hat{Z}=-\frac{\lambda_{u y}}{\lambda_{u z}} \hat{Y}
\end{gathered}
$$


Differentiating Equation (7) we have:

$$
\hat{P}_{y}=-\frac{1}{M_{3} M_{1}} L_{2} P_{y} Y \hat{\bar{r}}
$$

From Equations (a)-(c) and (9) we have:

$$
\begin{gathered}
\hat{R}=-\frac{1}{M_{3} M_{1}} L_{2} P_{y} Y \hat{\bar{r}} \frac{1}{D} \frac{\theta_{u z}}{\theta_{k 1 z}} \\
\hat{w}_{s}=\frac{1}{M_{3} M_{1}} L_{2} P_{y} Y \hat{\bar{r}} \frac{1}{D} \frac{\theta_{u z} \theta_{k i x}}{\theta_{k 1 z} \theta_{s x}} \\
\hat{w}_{u}=\frac{1}{M_{3} M_{1}} L_{2} P_{y} Y \hat{\bar{r}} \frac{1}{D}
\end{gathered}
$$

Differentiating Equation (4) we have:

$$
\hat{X}=0
$$

From Equations (f), (g) and (10) we have:

$$
\begin{gathered}
\hat{Y}=\frac{1}{M_{1}}\left[-\frac{1}{M_{3} M_{1}} L_{2} P_{y} Y \hat{\bar{r}} \frac{1}{D} \frac{\theta_{u z}}{\theta_{k 1 z}} L_{1}-\hat{\bar{r}} L_{2}\right] \\
\hat{Z}=-\frac{\lambda_{u y}}{\lambda_{u z}} \frac{1}{M_{1}}\left[-\frac{1}{M_{3} M_{1}} L_{2} P_{y} Y \hat{\bar{r}} \frac{1}{D} \frac{\theta_{u z}}{\theta_{k 1 z}} L_{1}-\hat{\bar{r} L_{2}}\right]
\end{gathered}
$$

where,

$$
\begin{gathered}
M_{1}=-\frac{\lambda_{u y}}{\lambda_{u z}}\left(\lambda_{k z}+\lambda_{k 1 z}\right)+\lambda_{k 1 y} \\
M_{3}=\frac{\alpha}{D}\left(w_{u} L_{u}+\frac{w_{s} L_{s} \theta_{k 1 x} \theta_{u z}}{\theta_{k 1 z} \theta_{s x}}\right)+P_{y} Y\left(\frac{L_{1}}{D M_{1}} \frac{\theta_{u z}}{\theta_{k 1 z}}-1\right) \\
L_{1}=K_{1} e_{R}-\frac{1}{\theta_{k x}+\theta_{k 1 x}} \sigma_{k, k 1}^{x}\left[\lambda_{k x} \theta_{k 1 x}-\lambda_{k 1 x} \theta_{k x}\right]+\frac{\sigma_{k, k 1}^{z}}{\theta_{k z}+\theta_{k 1 z}}\left[\lambda_{k 1 z} \theta_{k z}-\lambda_{k z} \theta_{k 1 z}\right] \\
L_{2}=K_{1} e_{r}-\frac{1}{\theta_{k x}+\theta_{k 1 x}} \sigma_{k, k 1}^{x}\left[\lambda_{k x} \theta_{k 1 x}-\lambda_{k 1 x} \theta_{k x}\right]+\frac{\sigma_{k, k 1}^{z}}{\theta_{k z}+\theta_{k 1 z}}\left[\lambda_{k 1 z} \theta_{k z}-\lambda_{k z} \theta_{k 1 z}\right] \\
D=\theta_{u y}-\frac{\theta_{u z} \theta_{k 1 y}}{\theta_{k 1 z}}
\end{gathered}
$$

\section{Effect of increase in formal capital endowment}

$$
\begin{gathered}
\hat{R}=-\frac{\theta_{u z}}{\theta_{k 1 z}} \hat{w}_{u} \\
\hat{w}_{u}=\frac{1}{D} \hat{P}_{y} \\
\hat{w}_{s}=\frac{1}{\theta_{s x} \theta_{k 1 z}} \frac{\theta_{k 1 x} \theta_{u z}}{D} \hat{P}_{y}
\end{gathered}
$$


Differentiating Equation (5) we have:

$$
\lambda_{u y} \hat{Y}+\lambda_{u z} \hat{Z}=0
$$

Differentiating Equation (6) we have:

$$
\lambda_{k 1 y} \hat{Y}+\hat{Z}\left\{\lambda_{k z}+\lambda_{k 1 z}\right\}=-\lambda_{k 1 z} \hat{a}_{k 1 z}-\lambda_{k z} \hat{a}_{k z}-\lambda_{k x} \hat{a}_{k x}-\lambda_{k 1 x} \hat{a}_{k 1 x}+K_{1} e_{R} \hat{R}-K_{1} e_{r} \hat{\bar{r}}
$$

Using Equations (d), (e) and the fact that:

$$
\begin{gathered}
\frac{\hat{a}_{k z}-\hat{a}_{k 1 z}}{\hat{R}-\hat{\bar{r}}}=\sigma_{k, k 1}^{z} \\
\frac{\hat{a}_{k x}-\hat{a}_{k 1 x}}{\hat{R}-\hat{\bar{r}}}=\sigma_{k, k 1}^{x} \\
\lambda_{k 1 y} \hat{Y}+\hat{Z}\left\{\lambda_{K Z}+\lambda_{k 1 z}\right\}=\hat{R} L_{1}+K_{f} \hat{K}_{f} \\
\hat{Z}=-\frac{\lambda_{u y}}{\lambda_{u z}} \hat{Y}
\end{gathered}
$$

Differentiating Equation (7) we have:

$$
\hat{P}_{y}=\frac{1}{M_{3}} P_{y} Y \frac{1}{M_{1}} K_{f} \hat{K}_{f}
$$

From Equations (a)-(c) and (19) we have:

$$
\begin{gathered}
\hat{w}_{u}=\frac{1}{M_{3}} \frac{1}{D} P_{y} Y \frac{1}{M_{1}} K_{f} \hat{K}_{f} \\
\hat{R}=-\frac{\theta_{u z}}{\theta_{k 1 z}} \frac{1}{M_{3}} \frac{1}{D} P_{y} Y \frac{1}{M_{1}} K_{f} \hat{K}_{f} \\
\hat{w}_{s}=\frac{\theta_{k 1 x}}{\theta_{k 1 z}} \frac{\theta_{u z}}{\theta_{s x}} \frac{1}{M_{3}} \frac{1}{D} P_{y} Y \frac{1}{M_{1}} K_{f} \hat{K}_{f}
\end{gathered}
$$

From Equation (4) we have:

$$
\hat{X}=0
$$

From Equations (f1), (g) and (21) we have:

$$
\begin{gathered}
\hat{Y}=\frac{L_{1}}{M_{1}}\left[-\frac{\theta_{u z}}{\theta_{k 1 z}} \frac{1}{M_{3}} \frac{1}{D} P_{y} Y \frac{1}{M_{1}} K_{f}\right] \hat{K}_{f}+\frac{1}{M_{1}} K_{f} \hat{K}_{f} \\
\hat{Z}=-\frac{\lambda_{u y}}{\lambda_{u z}}\left\{\frac{L_{1}}{M_{1}}\left[-\frac{\theta_{u z}}{\theta_{k 1 z}} \frac{1}{M_{3}} \frac{1}{D} P_{y} Y \frac{1}{M_{1}} K_{f}\right] \hat{K}_{f}+\frac{1}{M_{1}} K_{f} \hat{K}_{f}\right\}
\end{gathered}
$$

where,

$$
\begin{gathered}
M_{1}=-\frac{\lambda_{u y}}{\lambda_{u z}}\left(\lambda_{k z}+\lambda_{k 1 z}\right)+\lambda_{k 1 y} \\
M_{3}=\frac{\alpha}{D}\left(w_{u} L_{u}+\frac{w_{s} L_{s} \theta_{k 1 x} \theta_{u z}}{\theta_{k 1 z} \theta_{s x}}\right)+P_{y} Y\left(\frac{L_{1}}{D M_{1}} \frac{\theta_{u z}}{\theta_{k 1 z}}-1\right)
\end{gathered}
$$




$$
\begin{gathered}
L_{1}=K_{1} e_{R}-\frac{1}{\theta_{k x}+\theta_{k 1 x}} \sigma_{k, k 1}^{x}\left[\lambda_{k x} \theta_{k 1 x}-\lambda_{k 1 x} \theta_{k x}\right]+\frac{\sigma_{k, k 1}^{z}}{\theta_{k z}+\theta_{k 1 z}}\left[\lambda_{k 1 z} \theta_{k z}-\lambda_{k z} \theta_{k 1 z}\right] \\
D=\theta_{u y}-\frac{\theta_{u z} \theta_{k 1 y}}{\theta_{k 1 z}}
\end{gathered}
$$

\section{Effect of agricultural trade liberalization}

Differentiating Equations (1)-(3) we have:

$$
\begin{gathered}
\hat{w}_{u}=\frac{1}{\theta_{u z}}\left[\hat{P}_{z}^{*}-\theta_{k 1 z} \hat{R}\right] \\
\hat{R}=-\frac{1}{D}\left[\hat{P}_{y}-\frac{\theta_{u y}}{\theta_{u z}} \hat{P}_{z}^{*}\right] \\
\hat{w}_{s}=-\frac{1}{D} \frac{\theta_{k 1 x} \theta_{u y}}{\theta_{u z} \theta_{s x}} \hat{P}_{z}^{*}+\frac{\theta_{k 1 x}}{\theta_{s x}} \frac{\hat{P}_{y}}{D}
\end{gathered}
$$

Differentiating Equation (7) we have:

$$
\hat{P}_{y}=\frac{1}{N_{1}} \hat{P}_{z}^{*}
$$

From Equations (a1)-(c1) and Equation (28) we have:

$$
\begin{gathered}
\hat{R}=\frac{1}{D}\left[\frac{\theta_{u y}}{\theta_{u z}}-\frac{1}{N_{1}}\right] \hat{P}_{z}^{*} \\
\hat{w}_{u}=\frac{\theta_{k 1 z}}{\theta_{u z}} \hat{P}_{z}^{*} \frac{1}{N_{1}}+\left[1-\frac{\theta_{k 1 z} \theta_{u y}}{D \theta_{u z}}\right] \frac{\hat{P}_{z}^{*}}{\theta_{u z}} \\
\hat{w}_{s}=\frac{1}{D} \frac{\theta_{k 1 x}}{\theta_{s x}} \hat{P}_{z}^{*}\left[\frac{1}{N_{1}}-\frac{\theta_{u y}}{\theta_{u z}}\right]
\end{gathered}
$$

Differentiating Equation (5) we have:

$$
\lambda_{u y} \hat{Y}+\lambda_{u z} \hat{Z}=0
$$

Differentiating Equation (6) we have:

$$
\lambda_{k 1 y} \hat{Y}+\hat{Z}\left\{\lambda_{k z}+\lambda_{k 1 z}\right\}=-\lambda_{k 1 z} \hat{a}_{k 1 z}-\lambda_{k z} \hat{a}_{k z}-\lambda_{k x} \hat{a}_{k x}-\lambda_{k 1 x} \hat{a}_{k 1 x}+K_{1} e_{R} \hat{R}-K_{1} e_{r} \hat{\bar{r}}
$$

Using Equations (d), (e) and the fact that:

$$
\begin{gathered}
\frac{\hat{a}_{k z}-\hat{a}_{k 1 z}}{\hat{R}-\hat{\bar{r}}}=\sigma_{k, k 1}^{z} \\
\frac{\hat{a}_{k x}-\hat{a}_{k 1 x}}{\hat{R}-\hat{\bar{r}}}=\sigma_{k, k 1}^{x} \\
\lambda_{k 1 y} \hat{Y}+\hat{Z}\left\{\lambda_{K Z}+\lambda_{k 1 z}\right\}=\hat{R} L_{1} \\
\hat{Z}=-\frac{\lambda_{u y}}{\lambda_{u z}} \hat{Y}
\end{gathered}
$$


From Equation (4) we have:

$$
\hat{X}=0
$$

From Equations (f1), (g) and (10) we have:

$$
\begin{gathered}
\hat{Y}=\frac{L_{1}}{M_{1}} \frac{1}{D}\left[\frac{\theta_{u y}}{\theta_{u z}}-\frac{1}{N_{1}}\right] \hat{P}_{z}^{*} \\
\hat{Z}=-\frac{\lambda_{u y}}{\lambda_{u z}} \frac{L_{1}}{M_{1}} \frac{1}{D}\left[\frac{\theta_{u y}}{\theta_{u z}}-\frac{1}{N_{1}}\right] \hat{P}_{z}^{*}
\end{gathered}
$$

where,

$$
\begin{gathered}
M_{1}=-\frac{\lambda_{u y}}{\lambda_{u z}}\left(\lambda_{k z}+\lambda_{k 1 z}\right)+\lambda_{k 1 y} \\
M_{3}=\frac{\alpha}{D}\left(w_{u} L_{u}+\frac{w_{s} L_{s} \theta_{k 1 x} \theta_{u z}}{\theta_{k 1 z} \theta_{s x}}\right)+P_{y} Y\left(\frac{L_{1}}{D M_{1}} \frac{\theta_{u z}}{\theta_{k 1 z}}-1\right) \\
L_{1}=K_{1} e_{R}-\frac{1}{\theta_{k x}+\theta_{k 1 x}} \sigma_{k, k 1}^{x}\left[\lambda_{k x} \theta_{k 1 x}-\lambda_{k 1 x} \theta_{k x}\right]+\frac{\sigma_{k, k 1}^{z}}{\theta_{k z}+\theta_{k 1 z}}\left[\lambda_{k 1 z} \theta_{k z}-\lambda_{k z} \theta_{k 1 z}\right] \\
L_{2}=K_{1} e_{r}-\frac{1}{\theta_{k x}+\theta_{k 1 x}} \sigma_{k, k 1}^{x}\left[\lambda_{k x} \theta_{k 1 x}-\lambda_{k 1 x} \theta_{k x}\right]+\frac{\sigma_{k, k 1}^{z}}{\theta_{k z}+\theta_{k 1 z}}\left[\lambda_{k 1 z} \theta_{k z}-\lambda_{k z} \theta_{k 1 z}\right] \\
D=\theta_{u y}-\frac{\theta_{u z} \theta_{k 1 y}}{\theta_{k 1 z}} \\
N_{1}=\frac{P_{y} Y L_{1} \theta_{u y}}{M_{3} D M_{1} \theta_{u z}} \frac{1}{1+\frac{P_{y} Y L_{1}}{M_{3} M_{1} D}}
\end{gathered}
$$

\section{Derivation of stability condition}

$$
E D=\frac{\alpha\left(w_{s} L_{s}+w_{u} L_{u}\right)}{P_{y}}-Y
$$

For stability we require:

$$
\frac{\delta(E D)}{\delta P_{y}}<0
$$

Manipulating the excess demand function we have:

$$
\frac{\delta(E D)}{\delta P_{y}}=\frac{1}{P_{y}^{2}}\left[\alpha\left\{L_{s} \frac{\delta w_{s}}{\delta P_{y}}+L_{u} \frac{\delta w_{u}}{\delta P_{y}}\right\} P_{y}-\alpha\left(w_{s} L_{s}+w_{u} L_{u}\right)\right]-\frac{\delta Y}{\delta P_{y}}
$$

Further manipulation leads to:

$$
\frac{\delta(E D)}{\delta P_{y}}=\frac{1}{P_{y}^{2}}\left[\alpha\left\{\frac{w_{s} L_{s}}{P_{y}} \frac{\hat{w}_{s}}{\hat{P}_{y}}+L_{u} w_{u} \frac{1}{P_{y}} \frac{\hat{w}_{u}}{\hat{P}_{y}}\right\} P_{y}-\alpha\left(w_{s} L_{s}+w_{u} L_{u}\right)\right]-\frac{\hat{Y} Y}{\hat{P}_{y} P_{y}}
$$

By manipulating the above equation we find that the sufficient condition for stability is:

$$
-\frac{\lambda_{u y}}{\lambda_{u z}}\left(\lambda_{k z}+\lambda_{k 1 z}\right)+\lambda_{k 1 y}>0
$$

